\title{
Erratum to: Examining Fatal Opioid Overdoses in Marion County, Indiana
}

\author{
Bradley Ray • Kenna Quinet • Timothy Dickinson • \\ Dennis P. Watson • Alfarena Ballew
}

Published online: 21 February 2017

(C) The New York Academy of Medicine 2017

\section{Erratum to: J Urban Health}

DOI: 10.1007/s11524-016-0113-2

In the abstract for this article, it says " During the study period, 918 deaths involved heroin, and there were significant increases in accidental overdose deaths involving both heroin and fentanyl"

It should read: "918 deaths involved an opioid"

The online version of the original article can be found at http://dx. doi.org/10.1007/s11524-016-0113-2.

B. Ray $(\bowtie) \cdot \mathrm{K}$. Quinet $\cdot \mathrm{T}$. Dickinson

School of Public \& Environmental Affairs, Indiana University Purdue University Indianapolis, Indianapolis, IN, USA

e-mail: bradray@iupui.edu

D. P. Watson

Indiana University Richard M. Fairbanks School of Public Health, Indianapolis, IN, USA

A. Ballew

Marion County (Indiana) Coroner's Office, Indianapolis, IN, USA 